\title{
An Investigation of English-Mandarin-Malay Code Switching of a Singaporean Speaker
}

\author{
Gharizi Matiini \\ Indonesia Institute of Technology \\ ziedisanasini@yahoo.com
}

\begin{abstract}
The use of code switching is enormously popular in the countries with more than one language speakers. However, it is commonly used only by bilingual speakers in two languages. The present study aimed to investigate the code switching of a multilingual speaker in Singapore. Singapore is highly popular for its multilingual language use, Mandarin, English, and Malay. The data source in this study was a secondary data taken from a video site. The participant was a Singaporean called Terry. He spoke English switched with Mandarin and Malay. The present study applied Hoffman's (1991) and Muysken's (2000) dimensions of code switching characteristics. The results showed that there were 20 expressions of code switching produced by the participant. The analysis identified that the participant produced code switching mostly in Malay language than in Mandarin. During his speech, he commonly used inter-sentential switching and insertion switching from his English-Mandarin-Malay language. Tags and exclamation is the major switched code he made in the speech. While phrase is the least codes he created during the speech.
\end{abstract}

Keywords: code switching, inter-sentential switching, emblematic switching, insertion, and alternation

\section{INTRODUCTION}

Code switching or inter-sentential code is the language that changes the words, phrase, clause, or sentence from one language to another by the speakers in a conversation. Codeswitching "is switching from one language to another at a sentence boundary" (Thomason, 2001, p.132). The speakers generally change their languages because it is more comfortable to use other language for several special terms than stay with the same language and making confusion. "It happens when a speaker requires a particular code, in order to switch or mix one code to another and even create a new code in process" (Wardaugh, 1986, p. 101). From the definition, it can be inferred that code switching commonly occurs in bilingual community where the speakers communicate with more than one language. Thus, bilingualism cannot be separated from the code switching.

Hoffman (1991) explained that code switching occurs quite frequently in an informal conversation among people who are familiar and have a shared educational, ethnic, and socio-economic background (p.111). Hence, code switching takes place mostly in the university and office registers where the students and the workers who share the same knowledge of language communicate with each other. $\mathrm{Si}$ (2010) found that university students in India have been increasingly switching their language for $30 \%$ over the period of 1982 until 2004 (p. 402).

Hoffman (1991) also classified the code switching based on the position of the words, clause, or phrase in an utterance or sentence. He divided the code switching types into three aspects, inter-sentential switching, emblematical switching, and establishing continuity with the previous speaker. Inter-sentential switching occurs between clause or sentence boundary, where each clause or sentence is in one language or another. Here, the speaker produces different languages in different clauses or phrases as the example from Spanish-English utterance below.

"Tenia zapatos blancos, un poco, they were off-white, you know."

Emblematical switching consists of tags, exclamation, and certain set of phrases in one language which are inserted into an utterance otherwise in another, as when a Panjabi/English says:

"It's a nice day, hana?" (hai n? isn't it).

Another example is when an adult Spanish-American English says:

“...Oh! Ay! It was embarrassing! It was very nice, though, but I was embarrassed!” (Hoffman, 1991, p. 112)

Lastly, establishing continuity with the previous speaker takes place when the speakers continue the utterance of the previous speaker, as when one Indonesian speaker speaks in English and then his interlocutor tries to respond in English, yet, he switches again to Bahasa Indonesia.

Speaker 1: I can't get leave him 'coz I love him so much... Speaker 2: Correct! You got the point! Kata 'banget' itulah letak permasalahanmu sekarang ini" (Cakrawarti, 2011, p. 12).

However, the study would not take the last category as the type of code switching since the participant only performed a monologue speech and not talked to other speakers. Thus, the third category was not appropriate for the study and would be disregarded.

Another model of code switching was taken from Muysken (2000). He divided code switching into two major types, Insertion and alternation (p. 8). Insertion occurs when the speakers exchange a single-word or single-utterance 
expressions in the same speech as the example of EnglishHindi code switching below:

"Nothing is pakka."

'Nothing is certain'

"And we got married fat.afat"

'And we got married straight away’ (Si, 2011, p. 396)

Alternation is the code switching for the simultaneous switching of several constituents (Muysken, 2000 , p. 8). This code is usually longer and more complex than insertion so that alternation sometimes makes clause boundaries in an utterance. Therefore, it is much easier to notice alternation than insertion. Example below is the English-Hindi's code switching:

"ham kya kar rahem hă is none of your business"

"What we are doing is none of your businesses" ( $\mathrm{Si}, 2011, \mathrm{p}$. 397)

Many studies of code switching focus on bilingual speakers' conversation. However, there is only little investigation of code switching from multilingual speaker. Moreover, the present study concentrated on the monologue speech made by the speaker as other studied focalized intensely on the conversation between two speakers or among the speakers.

The present study aims to investigate the code switching of a multilingual speaker in Singapore. The analysis would apply Hoffman's (1991) and Muysken's (2008) types of code switching to find the major character of code switching produced by the speaker. The research question of the case study is written as follows: What character does English-Chinese-Malay code-switching bear from the speaker?

By identifying the types of the code switching, it was hoped that the study could detect whether the multilingual speaker could actually switch or mix his three languages in just one or two utterances. If he could do the code switching using his three languages, it would be possible for the monolingual or even bilingual speakers to master other languages and use three different codes switching without having fear to confuse their interlocutors during their communication. It would be also a decent news for the language teachers if the study could prove that multilingual speakers can switch their three codes. On the other words, teachers could teach their students more than one foreign language and switch them altogether in a conversation during the class.

\subsection{Limitation of the Study}

As mentioned in the background of study, the frameworks used in this study were from Hoffman's (1991) and Muysken"s (2000) dimensions of code switching. Both dimensions were chosen because they were considered suitable for the case of the study which the participant is a multilingual speaker who switches his code in three different languages and in many positions of his utterances.

\section{METHODOLOGY}

The study used a descriptive analysis method to identify the characteristics of the code switching used by a multilingual speaker. The result would be presented in a descriptive form using average numbers. The data source in this study was a secondary data taken from a video site (Azifah85, 2007). The researcher obtained the video after having seen it during the class in her magister degree program. The participant was a Singaporean called Terry. The author of the video had recorded and uploaded a monologue video of him, acting and talking about the situation and condition of Singaporeans in their daily life. In the four-minute video, he spoke English switched with Mandarin and Malay. The data were gathered firstly from searching a video related with the participant and downloading it to the computer. It was then being transcribed and decoded in order to find the code switching phenomena from his speech. Lastly, the codes of the code switching were tabled and analyzed for its characteristics of code switching.

In analyzing the data, the present study applied Hoffman's (1991) and Muysken's (2000) dimensions of code switching characteristics. After being transcribed and decoded, the codes then are being categorized based on the two frameworks of code switching types. When the categorization was done, the data were counted into percentage to discover the major characteristics of the code switching.

\section{FINDINGS AND DISCUSSION}

The section contains the result from the analysis code switching dimensions. In this finding, the characteristics of code switching were discovered using the total number of items and percentage. The results show that there were 20 expressions of code switching produced by the participant. The analysis identified that the participant produced code switching mostly in Malay language than in Mandarin. The first table showed the numbers and percentages of the characteristics of code switching from Hoffman's (1991) framework.

Table 1. Numbers and Percentage from Hoffman's Codeswitching Characteristics

\begin{tabular}{lll}
\hline $\begin{array}{l}\text { Types } \\
\text { switching }\end{array}$ & $\begin{array}{l}\text { Numbers of } \\
\text { expression }\end{array}$ & Percentage \\
\hline Inter-sentential & 7 & $35 \%$ \\
\hline Emblematic & 13 & $65 \%$ \\
\hline Total & 20 & $100 \%$ \\
\hline
\end{tabular}

From Table 1, it is clearly seen that the participant switched his language generally in the emblematic way. Almost two third of the percentage he made for emblematic switching. In addition, the participant produced emblematic switching majorly in Malay. He, for instance, said tags and exclamation in Malay such as $l a h ! A h !$ and $e h$ ! 
On the other hand, the rest of the percentage was inter-sentential switching with $35 \%$. Unlike Emblematic switching, he produced inter-sentential switching mostly in Mandarin. Single word such as suay (cool) and kop (took) are several expressions he made in Mandarin. Moreover, he also produced code switching in the form of phrase and clause in Mandarin such as Si Bei Slow (very very slow) and buay bei $k i$ (cannot afford to buy).

From the analysis, it can be inferred that the participant, during his speech, preferred to switch his language in Mandarin when he felt surprised about something. He also used Mandarin when he wanted to show his displeasure of his unlucky moments. However, it seemed like a habit for him to add tags and exclamation when he complained about his unlucky day. The result corresponded to what Wardaugh (1986) stated that the speaker needed a particular code to switch his language. In this study, the speaker commonly started his code switching with tags and exclamation. Moreover, the speaker usually changed his code when it was easier to talk in other language than English.

In general, the study found that the speaker could switch his code because he felt free to speak whatever he wanted in the video, where no one could interrupt his speech and where he could speak as slow as he intended to. Hoffman (1991) explained that code switching occurred quite frequently in an informal conversation. It probably proved that the speaker could mix his code with three languages because he talked in informal situation and he might believe that as long as he talked mostly in English, the viewers could understand with what he said.

The second table shows the numbers and percentages of the characteristics of code switching from Muysken (2000) framework.

Table 2. Numbers and Percentage from Muysken's Codeswitching Characteristics

\begin{tabular}{|c|c|c|}
\hline $\begin{array}{l}\text { Types of } \\
\text { Switching }\end{array}$ & $\begin{array}{l}\text { Numbers of } \\
\text { expression }\end{array}$ & Percentage \\
\hline Insertion & 18 & $90 \%$ \\
\hline Alternation & 2 & $10 \%$ \\
\hline Total & 20 & \\
\hline
\end{tabular}

It can be seen from Table 2 that insertion took the majority of the percentages with $90 \%$ while alternation obtained the least proportion of the percentages with $10 \%$. The insertion chunks produced by the speaker were mostly in the form of tags and exclamation. Meanwhile, the alternation switching made by the speaker is in the form of phrases such as Si Bei Slow (very very slow) and buay bei ki (cannot afford to buy).

The analysis confirmed that the speaker mainly produced single-word switching during his speech. He put the switched code generally in the front position in every clause he made as the predicate form without having any subject. The result was compatible with the statement from Thomason (2001) as he discovered that the position of code switching is usually at a sentence boundary. The study found that the speaker commonly switched his code in the clauseby-clause position or at the beginning or the ending of his sentence, usually in the form of the tags and exclamation where he usually put them either at the very end of the utterance or at the very beginning of it. Meanwhile, the alternation he produced was usually apart from previous utterance. He put the alternation phrases after having previous clause as the expression from his feeling. Both alternations he produced were about his feeling of displeasure.

\section{CONCLUSION}

The study has demonstrated the major characteristics of code switching from two different frameworks used by a multilingual speaker. During his speech, he commonly used inter-sentential switching and insertion switching from his English-Mandarin-Malay language. Tags and exclamation is the major switched code he made in the speech. While phrase is the least codes he created during the speech. Moreover, Mandarin language is mainly put as the single word and phrased while Malay language is used when the speaker says tags and exclamations.

The weakness raised from the study is that not all of Hoffman's framework could be used as the type of code switching due to the form of the speech was monologue. It possibly made the analysis became half reliable since Hoffman's Framework of code switching pointed out in the conversation situation. However, since almost frameworks of code switching dimensions are made for conversation, it is almost impossible to find the framework that is suitable for the study. Therefore, it was decided to use Hoffman's framework, as it is the most appropriate for the kind of position of the switched code in the utterances.

Further study is expected to have many other data of multilingual speaker since it is interesting to find which language that is intensively used by the speakers for certain position or part of speech of their utterances.

\section{REFERENCES}

Azifa85. (Producer). (2007). You Singaporean? Available from https://www.youtube.com/watch?v=aoZIF59Qsiw.

Cakrawarti. D.A. (2011). Analysis of code switching and code mixing in the teenlit Canting Cantiq by Dyan Nuranindya. (Unpublished bachelor's thesis). Dipenogoro University, Semarang.

Hoffmann, C. (1991). An introduction to bilingualism. London, New York: Longman.

Myers-Scotton, C. (1993) Duelling languages: Grammatical structure in codeswitching. Oxford: Oxford University Press.

Muysken, P. (2000). Bilingual speech: A typology of code mixing. Cambridge: Cambridge University Press.

Si, A. (2010). A diachronic investigation of Hindi-English code-switching, using Bollywood film scripts. International Journal of Bilingualism, 15(4), 388407. 
Thomason, S. G. (2001). Language contact: An

introduction. Edinburgh \& Washington DC:

Edinburgh University Press \& Georgetown University Press.

Wardhaugh, R. (2002). An Introduction to sociolinguistics. Malden, Mass: Blackwell Publishers. 